\title{
Obtaining and Characterizing a Polyester Resin and Cement Powder Composites
}

\author{
Luiz Guilherme Meira de Souza ${ }^{a *}$ (1), Edinesio Jales da Silva ${ }^{b}$, \\ Luiz Guilherme Vieira Meira de Souza ${ }^{c}$
}

\author{
${ }^{a}$ Universidade Federal do Rio Grande do Norte, Departamento de Engenharia Mecânica, Natal, RN, \\ Brasil \\ ${ }^{b}$ Universidade Federal do Rio Grande do Norte, Programa de Pós-Graduação em Engenharia \\ Mecânica, Natal, RN, Brasil \\ 'Instituto Federal de Educação, Ciência e Tecnologia do Rio Grande do Norte, Centro de Tecnologia em \\ Energia Eólica, João Câmara, RN, Brasil
}

Received: December 11, 2018; Revised: August 17, 2020; Accepted: September 12, 2020

The processes for obtaining and characterizing polyester resin $(\mathrm{R})$ matrix and cement powder (C) load composites were studied. Four composites were defined by the cement-to-resin mass ratio: $1.0 \mathrm{R}+0.25 \mathrm{C}, 1.0 \mathrm{R}+0.50 \mathrm{C}, 1.0 \mathrm{R}+0.75 \mathrm{C}$ and $1.0 \mathrm{R}+1.0 \mathrm{C}$. The selected manufacturing method was the wet compression molding. The composites were characterized by determining their tensile, flexural and impact strengths, density, water absorption levels, thermal and aging properties. The composite that presented the greater economic feasibility was $1.0 \mathrm{R}+1.0 \mathrm{C}$. The cement was found to have a filler load function. All composites showed lower mechanical strength compared to the matrix, with proportional decrease to the increased cement powder, with 50\% loss in tensile strength, $78 \%$ in flexural strength and $11.54 \%$ in impact strength for $1.0 \mathrm{R}+1.0 \mathrm{C}$. In this study, a $1.5 \mathrm{~m}^{2}$ table was manufactured by this composite $(1.0 \mathrm{R}+1.0 \mathrm{C})$. The cost for manufacturing the synthetic stone was lower than marble and granite stones, demonstrating the economic feasibility of the composites.

Keywords: Polyester resin, cement powder, composites, synthetic stone.

\section{Introduction}

Several environmental problems are generated by industrial and domestic waste, both due to improper disposal and the long decomposition time. In order to give an ecologically viable destination to these products, various materials are produced using this waste. The use of composite materials has been significantly increasing in several industrial areas of the world. In the automotive, shipbuilding, aeronautical, ballistic and artisanal areas, such insertion has become a priority due to characteristics of good aesthetics, lightness, and significant thermal and acoustic resistance ${ }^{1-7}$.

Polyester resins are the most used matrices in polymeric composites due to their low cost, easy processability, quick and cold curing, good esthetics, easy pigmentation and the possibility of using simple and accessible molds ${ }^{2-5,8}$. The high initial resistance Portland cement (CPV ARI) is composed of clinker, between 9590 and $100 \%$ of calcium sulfates and between 0 and $510 \%$ of carbon carbonatic material ${ }^{9}$, with aluminum, iron, calcium and sulfuric oxides and silicon dioxide as main chemical elements ${ }^{10}$. The MEK-P catalyst, styrene monomer, was used to accelerate the resin curing process. Carnauba wax was used as a release agent to obtain a better surface finishing and to facilitate the removal of the composite plates from the molds.

A study carried out by the Universidade Federal do Rio Grande do Norte, in Brazil, has manufactured synthetic

*e-mail: lguilherme@dem.ufrn.br stones that were used for manufacturing tables, chairs, and benches with low weight, reduced cost, and proper mechanical strength ${ }^{11}$.

Ribeiro ${ }^{12-14}$ studied the production of synthetic marble with a polyester matrix and load of calcified marble residue, through the resin transfer molding process using vacuum and vibro-compression, evaluating density, water absorption, mechanical resistance and the stains and scratches. The result was a stain resistant composite. Costa ${ }^{11}$ manufactured and studied a composite of polyester resin and marble powder produced by the cutting of ornamental stones. The composite proved to be viable in the replacement of natural marble and granite stones for the manufacture of tables, chairs, shelves, bathroom pottery, office partitions and structures that do not require mechanical strength.

Studies on the use of industrial waste in polymeric matrices are hardly available in the literature, when compared to ceramic matrices. Also, composites using cement powder in a polymeric matrix were not reported. Therefore, this study consisted of obtaining composites of polyester resin as matrix and cement powder as load, which seems to be a scientifically innovative idea. The materials were characterized in terms of mechanical, thermal and aging properties.

The purpose of the study was to evaluate the viability of application the proposed composites to the manufacturing of structures with low strength requirements. The idea is 
to provide lighter and more affordable materials than the conventionally used ones, such as marble, granite, and glass.

\section{Materials and Methods}

\subsection{Materials}

Orthophthalic polyester resin, high initial strength Portland cement, a catalyst and a mold release agent were chosen to manufacture the composites.

Two metal molds with dimensions according to the specific standards were used for producing the composite specimens for the mechanical tests. Mold 01, for tensile and bending tests, with $200 \mathrm{~mm} \times 200 \mathrm{~mm} \times 8 \mathrm{~mm}$, and mold 02 , for the impact test, with $120 \mathrm{~mm} \times 120 \mathrm{~mm}$ x $10 \mathrm{~mm}$. Another metal mold measuring $50 \mathrm{~mm}$ of internal diameter and $100 \mathrm{~mm}$ of height (mold 03) was used for producing the composite specimens for the thermal analysis.

\subsection{Methods}

\subsubsection{Composites manufacturing process}

The first step was to determine the maximum amount of cement that could be mixed with the resin to ensure the processability of the manual mixing process. The processability of the composites was compromised when more than a part of the cement was used in a part of the resin. This happened because, due to the viscosity increase, difficulties in homogenizing the mixture and in depositing the mixture in the molds started to arise. Four composites $\left(\mathrm{C}_{1}, \mathrm{C}_{2}, \mathrm{C}_{3}\right.$ and $\left.\mathrm{C}_{4}\right)$ were defined in terms of the amount of cement $(\mathrm{C})$ contained in the resin $(\mathrm{R})$, as shown by the nomenclature in Table 1. The flowchart in Figure 1 shows the main stages of the manufacturing process of the specimens for the characterization tests.

The wet compression molding manufacturing process was selected. It started by applying carnauba wax to the molds inside walls, bottom and cover. Then, based on the volume of the molds 01,02 and 03 , the mass of resin for each one was defined as $400 \mathrm{~g}$ of resin for mold $01,200 \mathrm{~g}$ for mold 02 and $300 \mathrm{~g}$ for mold 03 . Using a precision scale, the necessary mass of cement for each composition was defined.

Once the resin mass was defined, $2.0 \%$ by mass of catalyst (MEK-P) was added and manually mixed. Then, the cement powder was added in the proportions of each composite and, after homogenization, the molds were filled with the mixture. Between 10 to 15 minutes the mixture achieved the gel state. Finally, the molds were closed, and a two-ton compressive load was applied. In the thermal analysis specimens, compression was not performed. Since the applicability would be to obtain a thermal insulating material, for example, there would be a worsening in the results with

Table 1. Nomenclature used for each one of the composites.

\begin{tabular}{cc}
\hline Composites & Composition \\
\hline $\mathrm{C}_{1}$ & $1.0 \mathrm{R}+0.25 \mathrm{C}$ \\
\hline $\mathrm{C}_{2}$ & $1.0 \mathrm{R}+0.50 \mathrm{C}$ \\
\hline $\mathrm{C}_{3}$ & $1.0 \mathrm{R}+0.75 \mathrm{C}$ \\
\hline $\mathrm{C}_{4}$ & $1.0 \mathrm{R}+1.00 \mathrm{C}$ \\
\hline
\end{tabular}

the removal of air and voids that contribute to such property. After 24 hours under pressure, the molds were opened, the plates demolded, the burrs and protrusions were removed with sandpaper and the samples were cut with an electric saw, meeting the measures required by each test standard.

\subsubsection{Characterization of the composites}

The composites characterization comprised tensile, bending, impact, apparent density, water absorption, thermal and aging tests, thermogravimetric analysis (TGA), and scanning electron microscopy (SEM). Each test was performed pursuant to the guidelines of the applicable standard of the American Society for Testing and Materials-ASTM. Table 2 shows the standard adopted and the dimensions and number of specimens used in each test.

A SHIMADZU model AGS-X 300 universal machine was used in the tensile and bending tests. A LEIPZIG machine with a $0.937 \mathrm{~kg}$ hammer and a $220 \mathrm{~mm}$ rod analog pendulum was used in the impact test. In the apparent density test a Gehaka model DSL 910 digital densimeter was used. The water absorption test was performed using two aqueous media (distilled and marine water) for 60 days. In the thermal analysis test, a Decagon Devices model KD2 Pro analyzer kit was used. In the aging test, the specimens were placed on a slab and were exposed to environmental conditions for one year. Before and after exposure the bodies of proof were weighed and photographed to make an analysis of the degradation that occurred. The thermogravimetric analysis (TGA) was performed with a TA instruments model SDT Q600 simultaneous thermogravimetric and calorimetric analyzer, in an atmosphere of synthetic air with a $50 \mathrm{~mL} / \mathrm{min}$ flow rate, $10^{\circ} \mathrm{C} / \mathrm{min}$ heating rate and final temperature of $700{ }^{\circ} \mathrm{C}$. In the SEM test a Hitachi scanning electron microscope model TM 3000 was used, and the fracture surfaces of the specimens submitted to the tensile test were analyzed. The main goal was to evaluate the load/matrix interface and, consequently, the distribution of cement in the resin after impregnation, as well as the formation and propagation of damage.

\section{Results and Discussions}

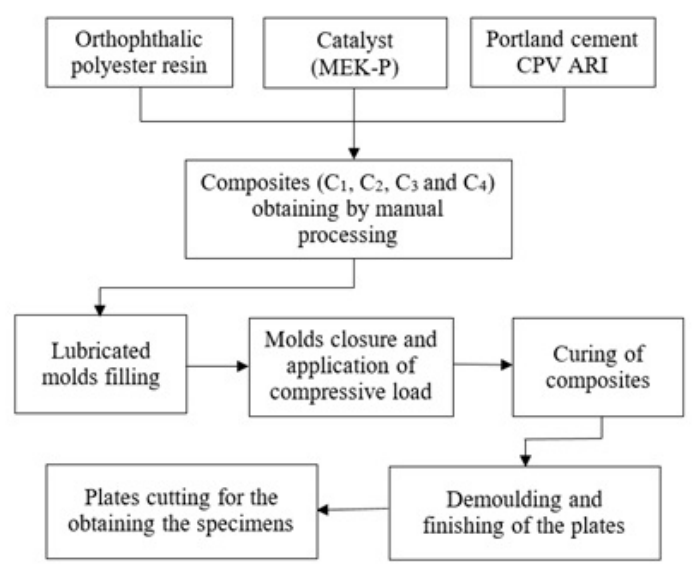

Figure 1. Steps of the manufacturing process of the specimens. 


\subsection{Tensile, flexural and impact strengths}

Table 3 presents the results of the tensile, bending and impact tests. The tensile and flexural resistance measured in the matrix were lower than those claimed by the manufacturer: $51.55 \mathrm{MPa}$ and $85.31 \mathrm{MPa}^{23}$, respectively. Such differences may be related to the resin handling and storage processes by local commercial resellers, since Andrade ${ }^{24}$ used resin obtained directly from the manufacturer and reported tensile strengths around $40.0 \mathrm{MPa}$.

As the amount of cement increased, the tensile strength of the composites decreased, making it evident that the cement powder weakened the matrix. $\mathrm{C}_{4}$ presented the worst result, with a decrease of $47.1 \%$ in relation to the matrix. Among the composites, the greatest strength drop occurred between $\mathrm{C}_{1}$ and $\mathrm{C}_{4}$. This $20.9 \%$ drop in tensile strength was already expected, since the increase in cement load was $75 \%$. As the cement cost compared to the resin cost is negligible, 2.4\%, the increase in cement powder brought greater economic viability for the composite, without significantly compromising its strength. It was observed a great decrease in the flexural strength of the composites in relation to the matrix. For $\mathrm{C}_{4}$ this decrease was of $71.7 \%$. The composite with the highest flexural strength is $\mathrm{C}_{1}, 56 \%$ more resistant than $\mathrm{C}_{4}$. The decrease in flexural strength was already expected, as the particulate material reduces the mechanical resistance of polymers, as shown in the literature ${ }^{25}$. Despite the good miscibility of the cement particles, the discontinuity generated in the matrix caused a strength decrease, due to the increased fragility of the composite, especially for composites with a higher percentage of cement load. Despite the good homogeneity of the resin and cement mixture, as the processability was manual, the occurrence of voids and cement agglomerates, evidenced in the SEM images, brought fragility to the resin.

Regarding impact resistance, the composites showed results very close to those of the polyester resin, proving the fragility of the produced composites. Once again, the filling function of the cement in the composites was evidenced. The impact energy absorption capacity decreased with the increase in the amount of cement in the composites, a behavior similar to the tensile and bending strengths ones. The most viable composite is $\mathrm{C}_{1}$, with a strength decrease of $6.0 \%$, and the worst result was presented by $\mathrm{C}_{4}$, with a strength decrease of $11.6 \%$, both in relation to the resin. It was demonstrated that the introduction of the cement powder in the resin brought a decrease in the impact energy absorption capacity. However, this decrease was small, not making the applicability of the composites unfeasible. These can be used in vibration damping structures on machine tools, for example.

\subsection{Apparent density}

The apparent density increased with the increase of the cement powder in the resin, as shown in Table 4. $\mathrm{C}_{1}$ has $15.2 \%$ higher density in relation to the resin. For $_{4}$, this value is of $38.9 \%$. The increase in the apparent density of the composites in relation to the resin was due to the higher density of the cement, which can vary from 1.2 to $1.6 \mathrm{~g} / \mathrm{cm}^{326}$. The reason for the decrease in volume when cement powder was mixed with the resin was in the diffusion process. The good diffusion of cement in the resin produced a homogeneous mixture, mainly due to the very low granulometry of the cement, around $75 \mu \mathrm{m}^{27}$. The increase in density of composites with a higher percentage of cement justified the decrease in their mechanical properties, due to their greater fragility.

\subsection{Absorption of water}

Table 5 shows the results of the distilled and marine water absorption tests. The composites presented a much higher absorption capacity than that of the polyester resin, due to the good compatibility between cement and water. This behavior was already expected, however, the water absorption capacity for the two studied aqueous media was

Table 2. Dimensions, quantities and standards used in the specimens.

\begin{tabular}{lccccc}
\hline \multicolumn{1}{c}{ Test } & $\begin{array}{c}\text { Length } \\
(\mathrm{mm})\end{array}$ & $\begin{array}{c}\text { Width } \\
(\mathrm{mm})\end{array}$ & $\begin{array}{c}\text { Thickness } \\
(\mathrm{mm})\end{array}$ & $\begin{array}{c}\text { Quantity per } \\
\text { formulation }\end{array}$ & ASTM \\
\hline Tensile & 200 & 25 & 8 & 6 & ASTM D3039/D3039M-17 $^{15}$ \\
\hline Bending & 200 & 25 & 8 & 6 & ASTM D7264/D7264M-15 $^{16}$ \\
\hline Impact & 100 & 10 & 10 & 6 & ASTM D6110-18 $^{17}$ \\
\hline Apparent density & 25 & 25 & 8 & 6 & ASTM D792-13 $^{18}$ \\
\hline Distilled water absorption & 25 & 25 & 8 & 6 & ${\text { ASTM D570-98(2010) e } 1^{19}}^{19}$ \\
\hline Marine water absorption & 25 & 25 & 8 & 6 & ASTM D570-98(2010) e ${ }^{19}$ \\
\hline Thermal analysis & $\phi 50$ & 100 & -- & 6 & ASTM D5930-1720 \\
\hline Aging & 200 & 25 & 8 & 1 & ASTM D1435-13 ${ }^{21}$ \\
\hline TGA & 5 & 5 & 3 & 1 & ASTM E2550-1722 \\
\hline SEM & 8 & 8 & 8 & 1 & --- \\
\hline
\end{tabular}

Table 3. Results of tensile, bending and impact tests for the composites and the polyester resin.

\begin{tabular}{cccc}
\hline Matrix/Composites & Tensile strength $(\mathrm{MPa})$ & Flexural strength $(\mathrm{MPa})$ & Impact strength $\left(\mathrm{J} / \mathrm{cm}^{2}\right)$ \\
\hline Resin & $22.252 \pm 0.625$ & $78.885 \pm 0.783$ & $0.251 \pm 0.003$ \\
\hline $\mathrm{C}_{1}$ & $14.872 \pm 0.455$ & $34.823 \pm 2.973$ & $0.236 \pm 0.002$ \\
\hline $\mathrm{C}_{2}$ & $14.115 \pm 0.435$ & $29.673+2.529$ & $0.229 \pm 0.002$ \\
\hline $\mathrm{C}_{3}$ & $12.372 \pm 0.373$ & $29.225 \pm 2.251$ & $0.225 \pm 0.004$ \\
\hline $\mathrm{C}_{4}$ & $11.768 \pm 0.340$ & $22.336 \pm 2.089$ & $0.222 \pm 0.001$ \\
\hline
\end{tabular}


low, reaching a maximum of $3.63 \%$ for distilled water and $4.07 \%$ for sea water. The increase in absorption between composites $\mathrm{C}_{1}$ and $\mathrm{C}_{4}$ in distilled water was of $76 \%$. In the marine environment, the composite with the best result was $\mathrm{C}_{1}$, and the worst result, $\mathrm{C}_{4}$, with an increase of $29.6 \%$ in relation to $\mathrm{C}_{1}$.

The absorption of marine water was higher when compared to the distilled water. Since seawater has a greater number of chemical elements, a greater ionization force is generated. This provides a greater amount of interactions with the resin, which an increase in water absorption.

\subsection{Thermal analysis}

Table 6 presents the results of the thermal analysis. Considering a thermal insulation application, the behavior of the composites was lower than that of polyester resin, due to the conductivity of the cement powder, $0.9 \mathrm{~W} / \mathrm{m} . \mathrm{K}^{28}$, being much higher than that of polyester resin. There was an increase in the analyzed thermal properties, K, C and D,

Table 4. Results of the apparent density tests for the composites and the polyester resin.

\begin{tabular}{cc}
\hline Matrix/Composites & Apparently density $\left(\mathrm{g} / \mathrm{cm}^{3}\right)$ \\
\hline Resin & $1.309 \pm 0.005$ \\
\hline $\mathrm{C}_{1}$ & $1.508 \pm 0.007$ \\
\hline $\mathrm{C}_{2}$ & $1.647 \pm 0.009$ \\
\hline $\mathrm{C}_{3}$ & $1.715 \pm 0.008$ \\
\hline $\mathrm{C}_{4}$ & $1.817 \pm 0.009$ \\
\hline
\end{tabular}

Table 5. Results of the distilled and marine water absorption tests for the composites and the polyester resin.

\begin{tabular}{ccc}
\hline Matrix/Composites & $\begin{array}{c}\text { Distilled water } \\
\text { absorption (\%) }\end{array}$ & $\begin{array}{c}\text { Marine water } \\
\text { absorption (\%) }\end{array}$ \\
\hline Resin & $1.01 \pm 0.001$ & $1.05 \pm 0.000$ \\
\hline $\mathrm{C}_{1}$ & $2.87 \pm 0.002$ & $3.14 \pm 0.003$ \\
\hline $\mathrm{C}_{2}$ & $3.10 \pm 0.002$ & $3.28 \pm 0.001$ \\
\hline $\mathrm{C}_{3}$ & $3.24 \pm 0.002$ & $3.84 \pm 0.004$ \\
\hline $\mathrm{C}_{4}$ & $3.63 \pm 0.002$ & $4.07 \pm 0.001$ \\
\hline
\end{tabular}

as the amount of cement in the polyester resin increased. The composite with the lowest thermal conductivity, $23.2 \%$ higher than the polyester resin, is $\mathrm{C}_{1}$. The one with the highest thermal conductivity, with an increase in relation to the $87.8 \%$ resin, is $\mathrm{C}_{4}$. The behavior of the thermal resistivity, the resistance to the passage of thermal waves through the material, was inversely proportional to that of thermal conductivity, decreasing as the amount of cement load in the composite increased, as expected.

The volumetric thermal capacity increased with the increase of the amount of cement powder in the resin, since the thermal capacity of the cement is significantly greater than that of the polyester resin, around $2.5 \mathrm{MJ} / \mathrm{m}^{3} \cdot \mathrm{K}^{29}$. The composite with the highest volumetric thermal capacity was $\mathrm{C}_{4}$ with an increase of $37 \%$ in relation to the resin and an increase of $31.8 \%$ in relation to the one with the lowest volumetric thermal capacity, $\mathrm{C}_{1}$. The same behavior was observed for the thermal diffusivity.

\subsection{Aging}

Table 7 presents the mass variation of the specimens in the natural environment aging test. The composites mass loss was much higher than that of the matrix, but not very significant (less than $0.5 \%$ ). The loss of mass due to weathering was greater in composites with higher amounts of cement. Therefore, the most viable composite for exposure to weather and climatic variations in all seasons is $\mathrm{C}_{1}$. However, it has a higher manufacturing cost due to the lesser amount of cement in the matrix. When performing a technical-economic analysis, it is concluded that the most viable composite is $\mathrm{C}_{4}$. The main change in the samples during the one-year exposure, occurred in the color. The polyester resin acquired a more yellowish hue.

\subsection{Thermogravimetric analysis (TGA)}

The graphs in Figure 2 contain the TGA and DTG curves that allow the identification of the thermal degradation stages for the matrix and the composites. Mass losses are generally caused by chemical reactions, such as thermal degradation, water loss, crystallization and combustion, and by physical transformations, such as vaporization, evaporation,

Table 6. Results of thermal analysis for the composites and the polyester resin.

\begin{tabular}{ccccc}
\hline Matrix/Composites & $\begin{array}{c}\text { Conductivity } \\
(\mathrm{W} / \mathrm{m} . \mathrm{K})\end{array}$ & $\begin{array}{c}\text { Resistivity } \\
\left(\mathrm{cm} .{ }^{\circ} \mathrm{C} / \mathrm{W}\right)\end{array}$ & $\begin{array}{c}\text { Thermal Capacity } \\
\left(\mathrm{MJ} / \mathrm{m}^{3} . \mathrm{K}\right)\end{array}$ & $\begin{array}{c}\text { Diffusivity } \\
\left(\mathrm{mm}^{2} / \mathrm{s}\right)\end{array}$ \\
\hline Resin & 0.155 & 645.90 & 1.272 & 0.109 \\
\hline $\mathrm{C}_{1}$ & 0.191 & 530.40 & 1.316 & 0.128 \\
\hline $\mathrm{C}_{2}$ & 0.224 & 455.30 & 1.468 & 0.154 \\
\hline $\mathrm{C}_{3}$ & 0.233 & 435.20 & 1.576 & 0.164 \\
\hline $\mathrm{C}_{4}$ & 0.291 & 350.00 & 1.735 & 0.172 \\
\hline
\end{tabular}

Table 7. Results of the mass variation of the aging tests for the composites and the polyester resin.

\begin{tabular}{cccc}
\hline Matrix/Composites & Initial mass $(\mathrm{g})$ & Final mass $(\mathrm{g})$ & Weight loss (\%) \\
\hline Resin & 50.038 & 50.021 & 0.040 \\
\hline $\mathrm{C}_{1}$ & 52.151 & 51.969 & 0.350 \\
\hline $\mathrm{C}_{2}$ & 58.655 & 58.436 & 0.374 \\
\hline $\mathrm{C}_{3}$ & 58.660 & 58.432 & 0.390 \\
\hline $\mathrm{C}_{4}$ & 60.530 & 60.280 & 0.410 \\
\hline
\end{tabular}



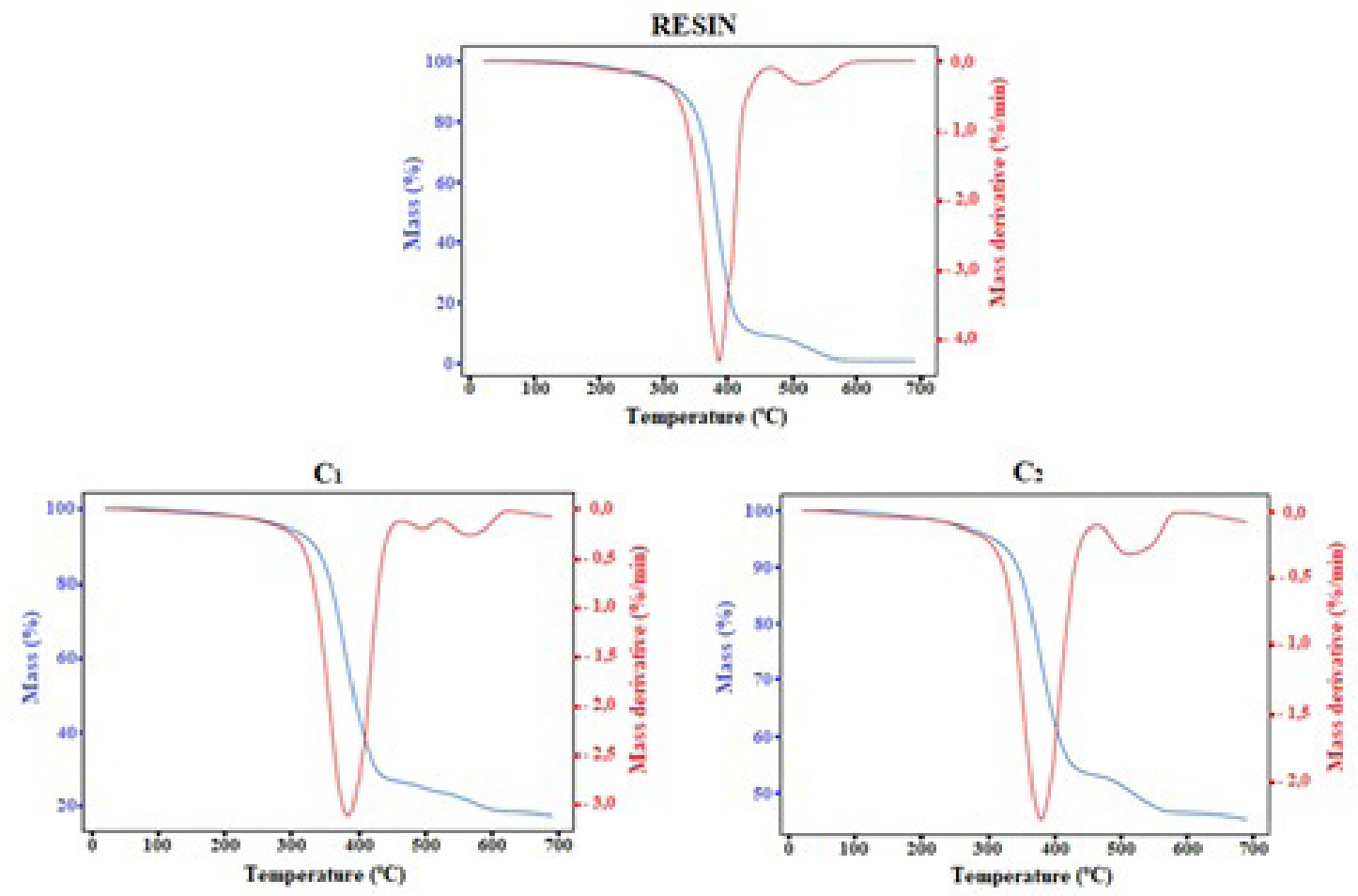

Cs

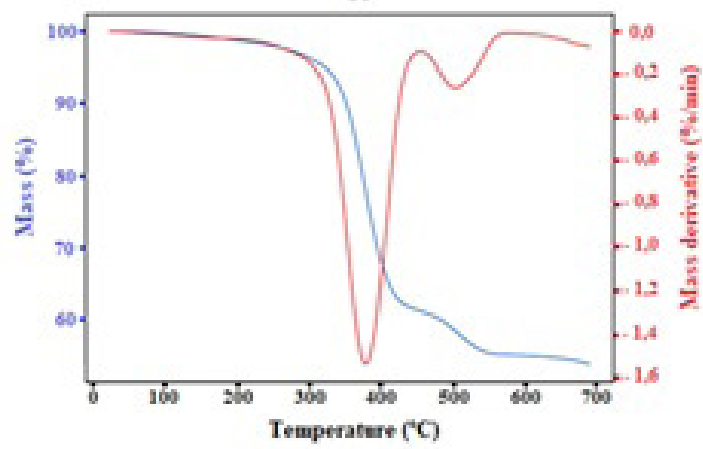

Figure 2. TGA curves for polyester resin composites.

sublimation, drying and desorption ${ }^{30}$. The ASTM E2550-17 standard $^{22}$ requires the determination of the mass variation and the onset temperature (temperature at which the loss of mass begins) of each reaction observed during the test. The values required by the standard are shown in Table 8 .

The composites showed greater resistance to thermal degradation than the resin. The mass loss decreased as the amount of cement powder load in the resin increased. The composite with the best performance showed a final mass close to $50 \%$, while the resin showed a final mass of $0.72 \%$, showing that the loss of mass suffered by the load was inferior than that of the resin. The resin and composites presented onset temperatures around $340^{\circ} \mathrm{C}$, showing, therefore, the same levels of thermal stability. The composites showed better results than the resin, being more resistant to thermal degradation in higher temperatures.

\subsection{Scanning electron microscopy (SEM)}

The scanning electron microscopy images of the fracture surfaces of the tensile test samples are shown in Figure 3. A great care was taken in the process of manufacturing the composites to avoid the presence of contaminants. The main objective was to provide a very homogeneous mixture between the two materials and to minimize the occurrence of voids and agglomerates, which could lead to reductions in mechanical strength. However, SEM images revealed the presence of many voids and agglomerates, generated by the cement concentration in certain regions. This occurred mainly in $\mathrm{C}_{3}$ and $\mathrm{C}_{4}$, the composites with higher mass percentages of cement. In addition, micro-cracks, fragile fractures and impurities were also found in all composites. However, these defects, did not compromise the structure 
Table 8. Tonset, Tpeak and mass loss values for the composites and the polyester resin.

\begin{tabular}{cccc}
\hline Matrix $/$ Composites & Onset temperature $\left({ }^{\circ} \mathrm{C}\right)$ & Peak temperature $\left({ }^{\circ} \mathrm{C}\right)$ & Mass variation $(\%)$ \\
\hline Resin & 344.07 & 386.88 & 99.28 \\
\hline $\mathrm{C}_{1}$ & 340.60 & 385.99 & 82.46 \\
\hline $\mathrm{C}_{2}$ & 337.20 & 380.06 & 54.96 \\
\hline $\mathrm{C}_{3}$ & 335.10 & 380.05 & 47.51 \\
\hline $\mathrm{C}_{4}$ & 334.01 & 383.10 & 46.28 \\
\hline
\end{tabular}

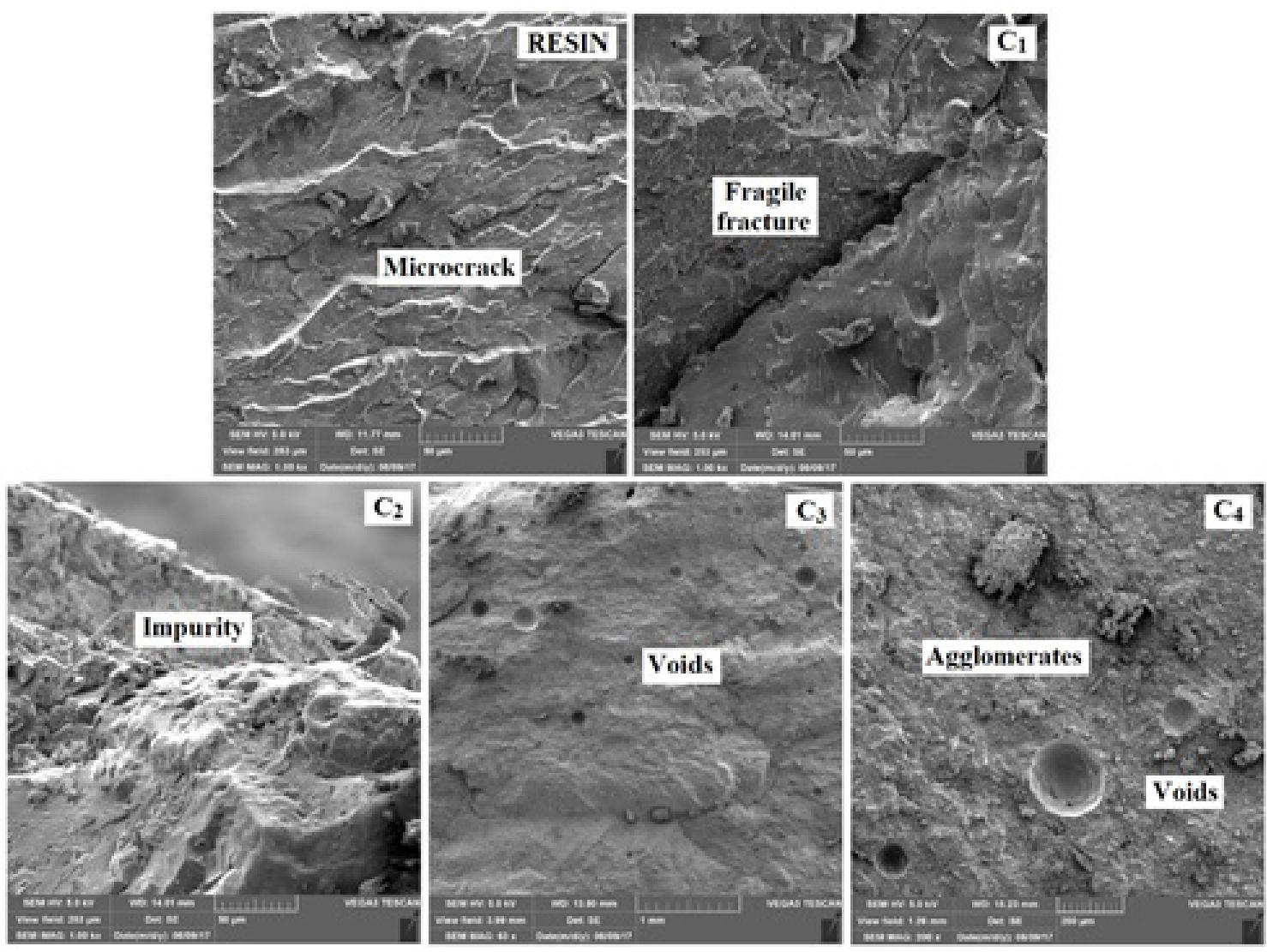

Figure 3. The SEM of all composites and polyester resin, highlighting the defects resulting from their manufacturing process.

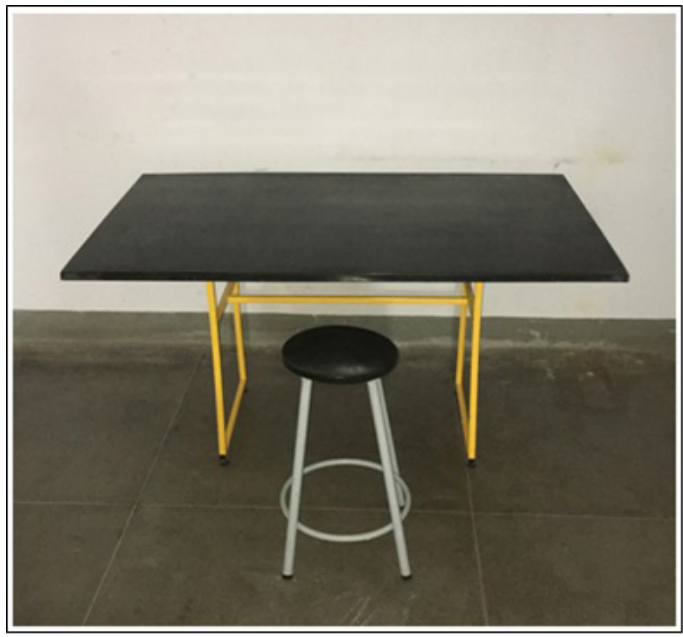

Figure 4. Table and bench manufactured with the $\mathrm{C}_{4}$ composite material. of the manufactured synthetic stones, as these pieces did not require high mechanical resistance.

\subsection{Composite application}

For the performance test, a table and a bench were manufactured with the $\mathrm{C}_{4}$ composite. These products were chosen because of their ease of manufacture and the fact that significant mechanical strength is not required in their main structure. The resulting products, shown in Figure 4, were up to $35 \%$ cheaper than granite and glass ones. They were tested for more than two years, being used under normal conditions, and showed no visible damage. This demonstrates their effectiveness for the proposed applications.

\section{Conclusions}

The manufacturing feasibility of the composites was demonstrated. As the cement powder performed a filling function in all the composites, they all presented a lower 
mechanical resistance than the matrix and should only be used in low mechanical load requirements applications. The composites presented a higher density, water absorption capacity and mass loss due to aging than the matrix, with an increase proportional to the growth of the percentage of cement. Better comparative results were obtained with the natural aging test. Considering a thermal insulation application, the behavior of the composites was lower than that of the resin, however they showed superior behavior in the thermogravimetric analysis, with a lower mass loss, demonstrating the positive influence of the cement load. The scanning electron microscopy showed the occurrence of microcracks, voids, impurities and agglomerates, which caused losses in the mechanical resistance of the composites, demonstrating that the manufacturing process of the composites needs to be optimized. The practical viability of the composites was also demonstrated. The most economically viable composite is the one with the highest percentage of cement, $\mathrm{C}_{4}$. An artificial stone made with this composite was 34\% lighter and $35 \%$ cheaper than marble/granite stones of the same dimensions. Therefore, it is technically and economically viable to use the proposed composite instead of ornamental stones widely used in decorative environments. A parameter that could have been evaluated is the compressive strength. The test results would allow the evaluation of the viability of using the composites to manufacture bricks, blocks and perforated walls, providing greater natural lighting and thermal comfort to the environments, with good aesthetics. The determination of the acoustic behavior, the vibration absorption capacity and the resistance to staining and scratching of the composites would also allow the determination of other applications for the proposed material.

\section{References}

1. Ahmed K, Nasir M, Fatima N, Khan KM, Zahra DN. Structural mass irregularities and fiber volume influence on morphology and mechanical properties of unsaturated polyester resin in matrix composites. J Adv Res. 2015;6(6):833-8. http://dx.doi. org/10.1016/j.jare.2014.06.007.

2. Alagaraja K, Dhamodharan A, Gopinatha K, Raj RM, Kumar KR. Fabrication and testing of fibre reinforced polymer composites material. J Mech Civ Eng. 2014;2:27-34.

3. Annamalai M, Ramasubbu R. Optimizing the formulation of e-glass fiber and cotton shell particles hybrid composites for their mechanical behavior by mixture design analysis. Mater Technol. 2018;52(2):207-14.

4. Bodur MS, Englund K, Bakkal M. Water absorption behavior and kinetics of glass fiber/waste cotton fabric hybrid composites. J Appl Polym Sci. 2017;134(47):45506. http://dx.doi.org/10.1002/ app.45506.

5. Portella EH, Romanzini D, Angrizani CC, Amico SC, Zattera AJ. Influence of stacking sequence on the mechanical and dynamic mechanical properties of cotton/glass fiber reinforced polyester composites. Mater Res. 2016;19(3):542-7. http:// dx.doi.org/10.1590/1980-5373-MR-2016-0058.

6. Sathishkumar TP, Naveen P, Navaneethakrishnan P, Satheeshkumar $\mathrm{S}$, Rajini N. Characterization of sisal/cotton fibre woven mat reinforced polymer hybrid composites. J Ind Text. 2017;47(4):42952. http://dx.doi.org/10.1177/1528083716648764.

7. Singh J, Kumar M, Kumar S, Mohapatra SK. Properties of glass-fiber hybrid composites: a review. Polym Plast Technol
Eng. 2017;56(5):455-69. http://dx.doi.org/10.1080/03602559 .2016 .1233271

8. Zonatti WF, Guimarães BMG, Duleba W, Ramos JB. Thermoset composites reinforced with recycled cotton textile residues. Textiles and Clothing Sustainability. 2015;1(1):1-12. http:// dx.doi.org/10.1186/s40689-014-0001-7.

9. ABCP: Associação Brasileira de Cimento Portland [homepage on the Internet]. 2018 [cited 2018 Aug 9]. Available from: http:// www.abcp.org.br

10. Rubert S. Contribution to the study of supersulfated cements: formulation and hydrationmechanisms [dissertation]. Pato Branco: Universidade Tecnológica Federal do Paraná; 2015.

11. Costa LCF. Obtaining and studying a composite of polyester matrix and charge of marble residues [dissertation]. Natal: Universidade Federal do Rio Grande do Norte; 2017.

12. Ribeiro CEG, Rodriguez RJS, Vieira CMF. Determination of apparent dry density for ternary mixture of crushed marble waste. In: Yurko J, Zhang L, Allanore A, Wang C, Spangenberger JS, Kirchain RE, et al., editors. EPD Congress 2014. Hoboken: John Wiley \& Sons; 2014. http://dx.doi.org/10.1002/9781118889664. ch10.

13. Ribeiro CEG, Rodriguez RJS, Vieira CMF. Production of ornamenta compound marble with marble waste and unsaturated polyester. In: Yurko J, Zhang L, Allanore A, Wang C, Spangenberger JS, Kirchain RE, et al., editors. EPD Congress 2014. Hoboken: John Wiley \& Sons; 2014. http://dx.doi.org/10.1002/9781118889664. ch16.

14. Ribeiro CEG, Rodriguez RJS. Influence of compaction pressure and particle ontent on thermal and mechanical behavior of artificial marbles with marble waste and unsaturated polyester. Mater Res. 2015;18(Suppl 2):283-90. http://dx.doi.org/10.1590/15161439.372314

15. ASTM: American Society for Testing and Materials. ASTM D3039/D3039M-17: standard test method for tensile properties of polymer matrix composite materials. West Conshohocken: ASTM International; 2017.

16. ASTM: American Society for Testing and Materials. ASTM D7264/D7264M-15: standard test method for flexural properties of polymer matrix composite materials. West Conshohocken: ASTM International; 2015.

17. ASTM: American Society for Testing and Materials. ASTM D6110-18: standard test method for determining the charpy impact resistance of notched specimens of plastics. West Conshohocken: ASTM International; 2018.

18. ASTM: American Society for Testing and Materials. ASTM D792-13: standard test methods for density and specific gravity (relative density) of plastics by displacement. West Conshohocken: ASTM International; 2013.

19. ASTM: American Society for Testing and Materials. ASTM D570-98(2010) e1: standard test method for water absorption of plastics. West Conshohocken: ASTM International; 2010.

20. ASTM: American Society for Testing and Materials. ASTM D5930-17: standard test method for thermal conductivity of plastics by means of a transient line-source technique. West Conshohocken: ASTM International; 2017.

21. ASTM: American Society for Testing and Materials. ASTM D1435-13: standard practice for outdoor weathering of plastics. West Conshohocken: ASTM International; 2013.

22. ASTM: American Society for Testing and Materials. ASTM E2550-17: standard test method for thermal stability by thermogravimetry. West Conshohocken: ASTM International; 2017.

23. EMBRAPOL: Induspol Industria de Polímeros Ltda [homepage on the Internet]. 2018 [cited 2018 June 9]. Available from: http://embrapol.com.br

24. Andrade MF. Obtaining and studying a composite with a polyester resin matrix and loading of chicken eggshell powder 
[dissertation]. Natal: Universidade Federal do Rio Grande do Norte; 2017.

25. Mota MKF. Obtaining and characterizing a polymeric matrix composite with vegetable bushing (luffa cylindrica) [thesis]. Natal: Universidade Federal do Rio Grande do Norte; 2016.

26. Castro AL, Liborio JBL, Pandolfelli VC. The influence of the type of cement on the performance of advanced concretes formulated from the computational method of dosing. Ceramics Magazine. 2011;57:341.

27. Oliveira AA. Determination of the granulometric composition of aggregates for concretes and mortars. Fortaleza: Technology
Center Department of Structural Engineering and Civil Construction, Federal University of Ceará; 2007.

28. Academy. of thermal conductivity. 2018 [cited 2018 Aug 9]. Available from: https://www.academia.edu/11415713/ tabela_de_condutividade_térmica_de_materiais_de_ construção

29. Alves LA. Coupled analysis of temperature and humidity in concrete at high temperatures [dissertation]. Rio de Janeiro: Universidade Federal do Rio de Janeiro; 2014.

30. Windmann G. Interpreting TGA curves. Schwerzenbach: Mettler Toledo GmbH; 2001. 